Viso: Cadernos de estética aplicada

Revista eletrônica de estética

ISSN 1981-4062

$N^{\circ} 29$, jul-dez/2021

http://www.revistaviso.com.br/
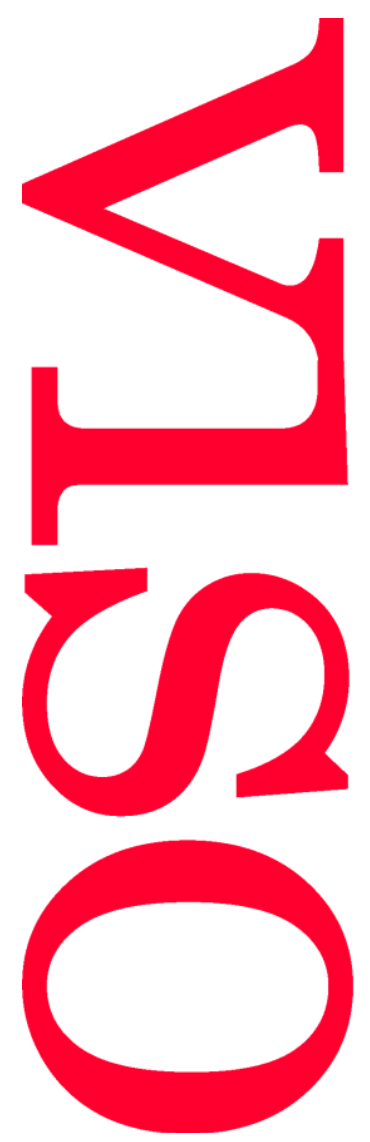

\title{
Walter Benjamin e Georges Didi-Huberman: um possível reencontro entre a história da arte e a filosofia
}

Taisa Palhares 


\section{RESUMO}

Walter Benjamin e Georges Didi-Huberman: um possível reencontro entre a história da arte e a filosofia

O texto busca indagar qual a relação entre história da arte e filosofia a partir do pensamento de Walter Benjamin e Georges Didi-Huberman. O fio condutor será o conceito de anacronismo histórico e sua relação com a montagem enquanto forma dialética de conectar obras de arte e imagens. Por fim, nota-se que, ao retomar o pensamento benjaminiano, Didi-Huberman ressalta a tarefa política subjacente à atividade do historiador da arte.

Palavras-chave

história; anacronismo; montagem; política

\section{ABSTRACT}

Walter Benjamin and Georges Didi-Huberman: A Possible Rapprochement between Art History and Philosophy

The text seeks to investigate the relationship between art history and philosophy based on the thought of Walter Benjamin and Georges Didi-Huberman. The guiding thread will be the concept of historical anachronism and its relationship with montage as a dialectical way of connecting works of art and images. Finally, it is noted that by resuming Benjamin's thought, Didi-Huberman highlights the political task underlying the activity of the art historian.

Keywords

history; anachronism; montage; politics 


\section{PALHARES, Taisa. "Walter Benjamin e Georges Didi- Huberman: um possível reencontro entre a história da arte e a filosofia". Viso: Cadernos de estética aplicada, v. $15, n^{\circ} 29$ (jul-dez/2021), p. 17-25.}

DOI: $10.22409 / 1981-4062 / v 29 i / 432$

Aprovado: 04.11.2021. Publicado: 30.01.2022.

(C) 2021 Taisa Palhares. Esse documento é distribuído nos termos da licença Creative Commons Atribuição-NãoComercial 4.0 Internacional (CC-BY-NC), que permite, exceto para fins comerciais, copiar e redistribuir o material em qualquer formato ou meio, bem como remixá-lo, transformá-lo ou criar a partir dele, desde que seja dado o devido crédito e indicada a licença sob a qual ele foi originalmente publicado.

Licença: http://creativecommons.org/licenses/by-nc/4.0/deed.pt_BR

Accepted: 04.11.2021. Published: 30.01.2022.

(C) 2021 Taisa Palhares. This document is distributed under the terms of a Creative Commons Attribution-NonCommercial 4.0 International license (CC-BY-NC) which allows, except for commercial purposes, to copy and redistribute the material in any medium or format and to remix, transform, and build upon the material, provided the original work is properly cited and states its license.

License: http://creativecommons.org/licenses/by-nc/4.0/ 
A partir da apresentação da pesquisadora Rosa Gabriella de Castro Gonçalves "Algumas Inquietações acerca do anacronismo na história da arte", gostaríamos de indagar brevemente sobre as consequências positivas que a história da arte, enquanto disciplina humanista, poderia tirar de uma possível aproximação ao pensamento estético-filosófico. Para tanto, iremos nos fixar no mote do texto de Castro, que retoma as relações entre o filósofo Walter Benjamin e o teórico francês Georges Didi-Huberman. Uma arqueologia crítica da história da arte nos conduz, para o último, ao questionamento dos modelos de tempo e da escolha das imagens que foram eleitas como seus objetos privilegiados de estudo. Diante do reconhecimento de que a "história da arte universal" é fundamentalmente uma narrativa sobre determinado gênero ou raça, uma nova escrita dessa narrativa pressupõe a ampliação dos conceitos de espaço e tempo históricos. Para além do alargamento do campo, resta-nos perguntar: em que medida isso não se impõe, sobretudo hoje, como uma tarefa política?

Em 2008, Giovanni Careri e Georges Didi-Huberman organizaram o colóquio internacional L'histoire de l'art depuis Walter Benjamin na École des hautes études en sciences sociales/Centre d'histoire et théorie des arts (Ehess/Cehta), no qual propunham interrogar o que são "a história, a arte e a história da arte", a partir do pensamento de Walter Benjamin, quer dizer "do lugar próprio deste pensamento". ${ }^{1}$ Logo, não se tratava apenas de retomar as reflexões benjaminianas sobre o Barroco, o Surrealismo, o cinema, a fotografia, a poesia de Baudelaire, etc. Na verdade, partia-se da constatação de que, se por um lado os historiadores do cinema, da literatura e da fotografia estavam familiarizados com o pensamento de Benjamin, o mesmo não poderia ser dito em relação aos historiadores da arte. 0 motivo de tal desconhecimento se daria pelo fato de seu pensamento ser, pelo menos à primeira vista, "horripilante" para um historiador da arte tradicional, no sentido de que sua posição diante de tal disciplina seria incompreensível. Didi-Huberman lembra que, ao mesmo tempo em que Benjamin afirmava em uma carta de 1923 que para ele algo como "uma história da arte" não existia, na mesma época, 
em um de seus currículos, o filósofo reconhecia a importância que o historiador da arte Alois Riegl, entre outros autores ligados à Escola de Viena, teria desempenhado em seus estudos. Pode-se dizer que Benjamin sempre teve um interesse permanente nas discussões sobre a historiografia da história da arte, como revelam suas resenhas e pequenos textos críticos, nos quais analisa os rumos dessa "disciplina" na passagem do século XIX para o XX.

Neste sentido, o teórico francês acredita que é a partir das reflexões de Benjamin sobre a filosofia da história que devemos encarar a tarefa de estabelecer uma "história crítica da arte" em que os modelos de temporalidade sejam questionados tomando como padrão o caráter "anacrônico" de toda obra ou imagem. Anacronismo que também será aquele da história em si: montagem de tempos heterogêneos que se tocam por afinidades e correspondências, nem sempre conscientes, e que cabe ao historiador "dispor" ou "repor", construindo novos anacronismos por meio de montagens.

Conforme explica Castro, a história da arte em sua vertente canônica defende a consonância eucrônica (como concordância do tempo), ou seja, a ideia de que para compreender o passado é necessário utilizar a chave do próprio passado, sem "projetar" o presente do historiador naquilo que é analisado. Essa postura (também equiparada ao "bom-senso" histórico) garantiria que se evitasse qualquer tipo de anacronismo, e seria a regra de ouro da história. Benjamin, em suas conhecidas teses "Sobre o conceito de história", associa esse posicionamento à ingenuidade do historiador positivista que busca conhecer o passado "como ele de fato foi". ${ }^{2}$ Ao contrário, para ele é apenas como uma "imagem", que perpassa veloz, ou relampeja no momento de perigo, que a verdade histórica se apresenta ao presente.

São as dinâmicas entre fulguração/fixação, proximidade/distância, revelação/ocultamento, aparecimento/desaparecimento nas e pelas imagens, tão presentes nas reflexões benjaminianas, que parecem atrair e 
inspirar o núcleo teórico da prática de Didi-Huberman. Para ele, Walter Benjamin "fundou uma certa história das imagens através de sua prática 'epistemo-crítica' da 'montagem' [Montage], que induz a um novo estilo de saber - logo, a novos conteúdos de saber - no âmbito de uma concepção original, e por assim dizer, subversiva do tempo histórico". ${ }^{3}$

Em diversos textos, Didi-Huberman não deixa de sublinhar o valor de exposição intrínseco a toda imagem, seja ela estática ou em movimento, artística ou documental, escrita ou figural. A imagem (ou a obra de arte) tem valor enquanto é exposta, enquanto lhe é restituído o lugar de sua visualidade. E essa não pode ser construída sem a certeza de que diferença e repetição temporal convivem no interior de toda imagem. Logo, a visualidade escapa à interpretação unilateral do tempo cronológico ou à superfície de sua visibilidade. Em seu estudo original sobre o minimalismo norte-americano, o estudo $O$ que vemos, o que nos olha, ele mostra como o ato de ver não se estrutura apenas como "máquina de perceber o real enquanto composto de evidências tautológicas perfeitamente descritíveis". ${ }^{4} \mathrm{O}$ dar a ver é antes uma operação inquietante, perturbadora, aberta, que cinde a superfície do objeto, e que se dá no espaço intersubjetivo no qual aquilo que vemos também nos olha. Por isso, toda interpretação de uma obra de arte é também um momento de perda, na medida em que a superfície do que é visto nos joga para o vazio, que recoloca a todo instante a distância.

Mas voltando brevemente ao pensamento de Benjamin, o conceito de "imagem dialética", que não podemos explorar aqui, é central para suas reflexões sobre uma nova historiografia crítica. Sua principal descrição encontra-se no seguinte fragmento seminal da Obra das Passagens.

Não é que o passado lança sua luz sobre o presente ou que o presente lança sua luz sobre o passado; mas a imagem é aquilo em que o ocorrido encontra o agora num lampejo, formando uma constelação. Em outras palavras: a imagem é dialética na imobilidade. Pois enquanto a relação do presente com o passado é puramente temporal e contínua, a 
relação do ocorrido com o agora é dialética não é uma progressão, e sim uma imagem, que salta. - Somente as imagens dialéticas são autênticas (isto é: não arcaicas), e o lugar onde a encontramos é a linguagem. Despertar. [N 2a, 4] $]^{5}$

A imagem dialética perpassa de forma fugaz e sua ambiguidade, que nunca se completa na síntese explicativa, nasce do encontro do agora do historiador com o ocorrido, que é mais do que um passado, morto e acabado, mas está sempre aberto a novas leituras e reconfigurações. Desta maneira, o conhecimento não produz uma história linear, mas uma constelação de imagens que são construídas pela leitura do filósofo-historiador, e fixadas em um conjunto heterogêneo e em movimento por meio da linguagem.

$\mathrm{Na}$ base dessa imagem encontra-se então a noção de tempo entrecruzado, que é, por exemplo, a essência das imagens proustianas originárias da memória involuntária. Em Proust, Benjamin dirá que a imagem do passado é antes de tudo uma reminiscência que coloca em jogo 0 universo de entrecruzamentos, de associações entre semelhanças nãosensíveis que são exemplares do mundo dos sonhos e não da vigília, ou seja, são diferentes da imagem que é lembrada pela memória voluntária, consciente, sujeita à tutela do intelecto. Essas imagens dialéticas que em Proust são fruto da memória involuntária também são fugazes, e mais, encontradas ao acaso, são como "a paisagem que se agita com o vento".

É então esse entrecruzamento temporal que se encontra no centro da noção de anacronismo de Didi-Huberman. Muito já se falou sobre a quase impossibilidade de construir uma história que se guiasse totalmente pela concepção benjaminiana de imagem dialética. E nesse sentido cabe perguntar se não seria no campo de uma história das artes ou das imagens o local de sua aplicabilidade. Parece que é nesse caminho que se insere o trabalho de Didi-Huberman, que por fim compreende a tarefa do historiador de arte como uma política das imagens. 
Por fim, vale notar que é na atividade de montagem que ambos os autores investem quando analisam a forma que teria uma tal história, retomando um recurso, como observa Castro, utilizado pelos artistas de vanguarda para romper com o espaço linear e fechado da arte tradicional. Pois só a montagem é capaz de expor uma copresença eficaz e conflituosa de acontecimentos, e preservar a sua multiplicidade, cuja reconstituição é sempre provisória e experimental. É o que Didi-Huberman identifica na Kriegsfibel de B. Brecht (1955), que em vez de ser política por meio de um engajamento ou tomada de partido, é uma tomada de posição diante dos acontecimentos, nem sempre coerentes, da história. Em sua cartilha, Brecht retoma o descontínuo que revela uma verdade fugaz:

\begin{abstract}
A imagem seria, então, pensada como "faísca" (é breve, é pouco) de uma verdade (é muito), conteúdo latente "chamado um dia a devorar" a ordem política estabelecida (é eventualmente eficaz). A montagem como tomada de posição ao mesmo tempo tópica e política, a montagem enquanto recomposição das forças nos ofereceria assim uma imagem do tempo que faz explodir a narrativa da história e a disposição das coisas. ${ }^{6}$
\end{abstract}

Parece-me então que é essa a tarefa ou desafio (não sei se essa é a palavra mais exata) que Didi-Huberman assume ao retomar o pensamento de Walter Benjamin. Não se trata apenas de empreender uma arqueologia da história da arte, mas de assumir que essa ação é também uma tomada de posição política, sem perder de vista a especificidade dos objetos em observação. Aqui o historiador da arte encontra o historiador materialista que pretende escrever a história a contrapelo, arrancando dessa maneira a tradição ao conformismo. Por isso, uma história da arte a partir do pensamento benjaminiano não revisita seus temas, mas articula seus conceitos. Como ele observou:

Mas Benjamin tocou no coração mesmo da questão que é a nossa, a saber, a relação entre imaginação e história. A imaginação do voyant tem apoio nos documentos do 
observador, mas ela se autoriza também a tomar todo esse material histórico a contrapelo, desorganizando, alegre e cruelmente, o que sugeriam as evidências causais da superfície. É preciso imagem para fazer história, sobretudo na época da fotografia e do cinema. Mas é preciso também imaginação para rever as imagens e, logo, para repensar a história. ${ }^{7}$

\section{Referências bibliográficas}

BENJAMIN, Walter. The Arcades project. Tradução de Howard Eiland e Kevin McLaughlin. Cambridge: Harvard University Press, 1999.

Magia e técnica, arte e política. Tradução de Paulo Sérgio Rouanet. São Paulo: Brasiliense, 1994.

DIDI-HUBERMAN, Georges. O que vemos, o que nos olha. Tradução de Paulo Neves. São Paulo: Editora 34, 1998.

DIDI-HUBERMAN, Georges (org.). L'histoire de l'art depuis Walter Benjamin. Paris: Editions Mimésis, 2015a.

Diante do tempo: história da arte e anacronismo das imagens. Tradução de Vera Casa Nova e Márcia Arbex. Belo Horizonte: Editora da UFMG, 2015b.

Quando as imagens tomam posição: o olho da história, v. I. Tradução de Cleonice Paes Barreto Mourão. Belo Horizonte: Editora da UFMG, 2017.

\footnotetext{
Taisa Palhares é professora do Departamento de Filosofia da UNICAMP.

${ }^{1}$ DIDI-HUBERMAN, 2015a, p. 9.

2 BENJAMIN, 1994, p. 224.

${ }^{3}$ DIDI-HUBERMAN, 2015b, p. 52.

${ }^{4}$ DIDI-HUBERMAN, 1998, p.77.

${ }^{5}$ BENJAMIN, 1999, p. 462.

${ }^{6}$ DIDI-HUBERMAN, 2017, p. 118.

7 DIDI-HUBERMAN, 2017, p. 235.
} 